\title{
UMA ANÁLISE DO AMBIENTE MERCADOLÓGICO DE UMA EMPRESA DO SETOR METAL MECÂNICO SOB AS PERSPECTIVAS DE PORTER
}

\author{
AN ANALYSIS OF THE MARKETING \\ ENVIRONMENT OF A METAL MECHANICAL \\ INDUSTRY UNDER THE PORTER'S PERSPECTIVE
}

Recebido 02/05/2011

Aceito 28/06/2012

Luis Felipe Dias Lopes ${ }^{1}$, Fransana Petter Machado², Fillipe Grando Lopes ${ }^{3}$, Mauren Pimentel Lima ${ }^{4}$, Vânia Medianeira Flores Costa ${ }^{5}$, Diana Dellla Mea da Silva ${ }^{6}$

\section{RESUMO}

Em um mercado altamente competitivo, o qual os consumidores estão cada vez mais exigentes, as empresas, para manterem-se, buscam estratégias competitivas, apontando como alternativa a diferenciação na Qualidade de seus produtos. Para que esse objetivo seja alcançado, as empresas norteiam suas estratégias para um sistema de Qualidade adequado, elaborando, então, um Planejamento Estratégico da Qualidade. Este trabalho caracteriza-se por ser uma pesquisa exploratória, quali-quantitativa, que apresenta observações efetuadas em uma empresa do setor metalúrgico da cidade de Santa Maria-RS, e que tem como proposta descrever como o Planejamento Estratégico está comprometido com a Qualidade, além de observar os ambientes internos e externos da empresa, através da elaboração da Matriz SWOT e da percepção das cinco forças competitivas de Porter (1990). Foi observado o Custo da Má Qualidade na empresa, abordando as falhas e os defeitos causados por ela, e, ainda, o quanto isso representou no faturamento. Foi possível abordar o quanto a empresa perdeu em receita de vendas devido às falhas no processo operacional. Diante disto, este trabalho serve como um alerta aos administradores sobre os custos que a falta de um controle de Qualidade pode apresentar para a empresa, e sobre o fato de que a implantação de um sistema da Qualidade pode ser vista como uma ferramenta para a promoção de melhorias, e não só como um conjunto de normas que permitem a obtenção de um certificado.

Palavras-chave: Qualidade; Planejamento estratégico da qualidade; Custo da Má Qualidade; Matriz SWOT; Sistema de qualidade.

\footnotetext{
${ }^{1}$ Possui graduação em Matemática Licenciatura Plena pela Faculdade Imaculada Conceição, mestrado em Engenharia de Produção pela Universidade Federal de Santa Maria - UFSM e doutorado em Engenharia de Produção pela Universidade Federal de Santa Catarina - UFSC. Atualmente é Professor Associado II da Universidade Federal de Santa Maria - UFSM. Santa Maria, Rio Grande do Sul, Brasil. E-mail: Iflopes67@yahoo.com.br.

2 Possui graduação em Administração pela Universidade Federal de Santa Maria - UFSM e cursa pós-graduação em MBA em Planejamento e Gestão Estratégica na Faculdade Internacional de Curitiba. Atualmente é administradora - Idema Peças e Máquinas Agrícolas Ltda. Santa Maria, Rio Grande do Sul, Brasil. E-mail: franpetter@yahoo.com.br.

${ }^{3}$ Atualmente é graduando em Desenho Industrial e bolsista PIBIC/CNPq. Santa Maria, Rio Grande do Sul, Brasil. E-mail: fill. zaz@terra.com.br.

${ }^{4}$ Possui graduação em enfermagem pelo Centro Universitário Franciscano - UNIFRA. Atualmente é mestranda em Administração na Universidade Federal de Santa Maria - UFSM. Santa Maria, Rio Grande do Sul, Brasil. E-mail: maurenlima@terra.com.br.

${ }^{5}$ Possui graduação e mestrado em Administração pela Universidade Federal de Santa Maria - UFSM e doutorado em Administração pela Universidade Federal da Bahia - UFBA. Atualmente é professora Adjunta do Departamento de Ciências Administrativas da Universidade Federal de Santa Maria - UFSM. Santa Maria, Rio Grande do Sul, Brasil. E-mail: vaniaflores2006@yahoo.com.br.

${ }^{6}$ Possui graduação em Administração e especialização em Gestão de Pessoas e Marketing pelo Centro Universitário Franciscano. Atualmente é mestranda do Programa de Pós-Graduação em Engenharia da Universidade Federal de Santa Maria - UFSM. Santa Maria, Rio Grande do Sul, Brasil. E-mail: adm.dianasm@gmail.com.
} 


\section{ABSTRACT}

In a highly competitive market where consumers are increasingly demanding, the companies, in order to maintain themselves, seek competitive strategies, bringing as an alternative the differentiation in their products quality. To achieve this goal, companies guide their business strategies for an apropriate quality system, developing a Strategic Quality Planning. This paper presents the observation made in a metallurgical industry from Santa Maria with the purpose to describe how the Strategic Planning is committed to quality, in addition to an observation of its internal and external environments through the development of the SWOT matrix and the perception through the five competitive forces of Porter (1990). It was observed the cost of poor quality in the company, addressing to the flaws and defects caused by its lack and how much it represented in the company incomes. It was possible to notice how much the company lost in sales according to the flaws in the operational process. This paper intends to warn the administrators about the costs due to a lack of quality presented by the company and that the implementation of a quality system is seen as a tool to promote improvements and not only as a set of rules to obtain a certificate. Keywords: Quality; Strategic quality planning; Cost of poor quality; SWOT matrix; Quality system.

\section{INTRODUÇÃO}

O Planejamento Estratégico (PE) tem chamado à atenção da alta administração das empresas, destacando-se por salientar medidas positivas que uma empresa poderá tomar diante de ameaças, tirando proveito de oportunidades possivelmente encontradas em seu mercado.

Atualmente, podemos encontrar uma série de interpretações sobre o PE. Uma delas foi definida por Kotler (1992, p. 63), que apresenta o PE como sendo "o processo gerencial de desenvolver e manter uma adequação razoável entre os objetivos, recursos da empresa e as mudanças e oportunidades de mercado".

Nesse contexto, pode-se confirmar a importância de uma estratégia que dirija a organização para atingir seus objetivos. Não importando a natureza da empresa, os empresários estão cada vez mais comprometidos com suas estratégias. De acordo com Wright (2000), estratégia são os planos da alta administração para alcançar resultados coerentes com a missão e os objetivos gerais da organização.

O objetivo do PE é orientar e reorientar os negócios e produtos da empresa de modo a gerar lucros e crescimento satisfatório. Para isso, existem diversos tipos de estratégias que as empresas podem aderir. Contudo, essa escolha está vinculada à cultura organizacional da empresa.

Implantar uma estratégia é fazer escolhas, definir como sua empresa vai se destacar, se diferenciar no mercado. É definir onde sua organização está, e aonde você quer que ela chegue, escolhendo, para isso, o melhor caminho. As escolhas estratégicas representam os caminhos eleitos pela empresa para alcançar vantagem competitiva, cuja especificação é questão fundamental do $P E$, pois ela estabelece o contexto para os planos funcionais dos diversos setores/processos (PORTER, 1990).

A relevância deste trabalho está em analisar a existência de um PE da Qualidade no setor de produção de uma empresa metalúrgica da cidade de Santa Maria-RS, e o impacto causado pela Má Qualidade no seu faturamento, devido a Perda de Receita de Vendas. Através da construção da Matriz SWOT da empresa, o trabalho visa, além de apresentar a análise baseada nas cinco forças propostas por Porter (1990), relatar quais são as forças, fraquezas, ameaças e oportunidades encontradas pela empresa.

Esta pesquisa justifica-se uma vez que, as organizações estão sendo cada vez mais pressionadas por um mercado altamente concorrente e com recursos limitados, exigindo, assim, que seus gestores tomem atitudes imediatas para garantir a sobrevivência das empresas. 
Os capitais materiais e intelectuais disponíveis devem ser investidos na operacionalização de estratégias estruturadas, que possibilitem o desenvolvimento competitivo a curto, médio e longo prazo. Nesse sentido, um erro no posicionamento estratégico pode comprometer significativamente a estrutura da organização.

Em virtude disso, a presente pesquisa baseia-se em um referencial teórico para informar os gestores sobre os riscos que podem sofrer quando não ocorre um alinhamento entre os objetivos traçados pela empresa e suas atitudes, gerando desperdício de tempo e capital.

\section{PLANEJAMETO ESTRATÉGICO}

Atualmente, a gestão empresarial envolve a determinação de objetivos, a projeção e a construção de estruturas organizacionais adequadas, a mobilização dos recursos necessários para o alcance dos objetivos, além da necessidade do desenvolvimento de um processo de direção coerente, lógico e criativo, que ordene o comportamento das pessoas na organização e que possibilite cursos alternativos de ação na busca dos melhores resultados possíveis (PINHEIRO, 1996).

Sendo assim, o planejamento estratégico é uma ferramenta para contribuir com a organização, no sentido de antecipar não apenas as ações que devem ser tomadas, mas também a sua missão, a sua visão, os seus objetivos, as estratégias e os programas individuais (GOMES et al., 2012).

Os valores, segundo Farias Filho e Salles (1997), são as crenças que formatarão a consciência coletiva da comunidade da organização. Essa consciência é que vai definir e julgar os efeitos ou resultados das ações integradas realizadas pela organização.

Os valores têm como função orientar a vida da empresa e guiar o comportamento dos seus membros. Eles são determinantes da rotina diária da organização, já que orientam a vida do indivíduo e determinam a sua forma de pensar, de agir e de sentir (TAMAYO et al., 2000).

\subsection{As forças competitivas de Porter}

De acordo com Porter (1990), a caracterização de uma indústria, do ponto de vista estratégico, efetua-se pela diferenciação dos fatores de competitividade decisivos na estrutura dessa indústria, na sua evolução e nas relações que se estabelecem entre eles. O autor aponta cinco fatores, os quais define como "as cinco forças competitivas". São eles:

- Entrantes potenciais: novas empresas que entram no ramo dos negócios para ganhar parcelas de mercado, ocasionando a diminuição da rentabilidade dos demais participantes.

- Poder de Barganha dos Fornecedores: refere-se ao poder de barganha dos fornecedores sobre as empresas do setor, ameaçando elevação de preços, diminuição de Qualidade etc., e implicando também a diminuição da rentabilidade.

- Poder de Barganha dos Clientes: os compradores, em função de seu poder de barganha, podem forçar a baixa dos preços da indústria, bem como a melhoria da Qualidade dos produtos ou serviços, acirrando, assim, a concorrência.

- Substitutos: força caracterizada por empresas que fabricam produtos substitutos aos produzidos por outra, podendo reduzir a lucratividade das demais, pois estes se apresentam como uma alternativa de preço e Qualidade para os consumidores.

- Concorrentes: empresas de um mesmo ramo de negócios, que disputam parcelas no mercado, podendo configurar-se por concorrência de preços, adição de valor a produtos e serviços, entre outros. 
Essa classificação apresenta notável dinamismo na caracterização de uma indústria. Cada uma dessas forças competitivas tem intensidade variável em função do tipo de negócio no qual a empresa se encontra. Dessa forma, dependendo do tipo de negócio, tais forças podem representar sérias ameaças para as empresas.

\subsection{Análise da Matriz SWOT}

Esta análise foi desenvolvida por Kenneth Andrews e Roland Christensen, dois professores da Harvard Business School (BICHO; BAPTISTA, 2006).

O termo SWOT resulta da conjugação das iniciais das palavras anglo-saxônicas Strengths (forças), Weaknesses (fraquezas), Opportunities (oportunidades) e Threats (ameaças). Assim, a análise SWOT corresponde à identificação integrada, por parte de uma organização, dos principais aspectos que caracterizam a sua posição estratégica num determinado momento, tanto a nível interno como externo, acerca da forma como a organização se relaciona com o seu meio envolvente (BICHO; BAPTISTA, 2006).

Devido a sua simplicidade de aplicação, tanto para empresas, como para produtos e serviços, o modelo SWOT é amplamente utilizado, apesar de apresentar algumas limitações devido à subjetividade de julgamento e também à dificuldade de discernir quais os fatores internos e externos. Entretanto, por ser representado geralmente em forma de matriz, como pode ser observado no quadro 01 , o modelo SWOT permite que seja demonstrada a situação atual do negócio de maneira simples e de fácil entendimento (ALVES et al., 2007).

A análise SWOT fornece, segundo Machado (2005), uma orientação estratégica bastante significativa, pois permite:

- Eliminar pontos fracos nas áreas que a empresa enfrenta ameaças graves da concorrência e disposições desfavoráveis diante do negócio;

- Abranger oportunidades encontradas a partir da análise dos seus pontos fortes;

- Retificar pontos fracos nos quais a organização vislumbra oportunidades potenciais;

- Monitorar seus pontos fortes, evitando riscos e incertezas no futuro.

\subsection{Planejamento Estratégico da Qualidade}

De acordo com Robles Jr. (2003), é desde a era industrial que as empresas vêm se preocupando com a Qualidade de seus produtos. Porém é mais recentemente que elas estão focando sua atenção na Qualidade dos processos, para atender seus consumidores. Essa preocupação é conhecida por Controle da Qualidade Total (TQC, Total Quality Control).

A Qualidade nas empresas, para Feigenbaum (1994, p. 11), possui o significado de "desempenho máximo a fim de satisfazer certas condições do cliente".

Já Juran (1994), utiliza o termo Gerência Estratégica da Qualidade (GEQ) para referir-se ao PE da Qualidade e o define como sendo um processo estruturado que visa estabelecer metas de longo prazo para a Qualidade, envolvendo os níveis mais altos da organização e especificando os meios que serão utilizados para a implementação de tais metas.

De acordo com Baisch et. al. (2012), o planejamento estratégico deve ser aplicado a unidades e indivíduos, pois, assim, possibilita que o pensamento estratégico não se restrinja apenas à organização como um todo, mas que englobe os vários estratos da organização, inclusive o profissional, facilitando a implementação do plano estratégico. 
OPlanejamento da Qualidade destaca-se nogerenciamento da Qualidade, pois visa desenvolver produtos e processos que atendam às necessidades e aos desejos dos clientes (JURAN, 1995).

Por essas e outras razões que cada vez mais as empresas buscam sistemas de Qualidade com reconhecimento social. Esse tipo de preocupação acarretou o desenvolvimento das normas de sistema da Qualidade que complementam os requisitos dos produtos constantes das especificações técnicas.

\subsection{Custo da Qualidade}

Com mercado altamente competitivo, em que, para conquistar novos clientes, a inovação é uma preocupação constante das empresas, e com o fato de que os consumidores dispõem de maior variedade de produtos a sua disposição, as empresas buscam oferecer para os clientes, que estão cada vez mais exigentes, produtos de alta Qualidade como um diferencial. A Qualidade e os preços dos bens ou serviços são frequentemente questionados e reivindicados pelos clientes.

De acordo Piana e Erdmann (2011), a qualidade está fundamentada em princípios que procuram atender à expectativa dos clientes, quanto a produtos e serviços, e às necessidades técnicas da organização, quanto à minimização dos erros e custos relacionados.

Segundo Almeida e Idrogo (2004), o controle dos custos e da Qualidade poderá apoiar a estratégia competitiva. Estudar os custos da Qualidade e da Má Qualidade numa empresa é importante e imprescindível para a tomada de decisões que incidem diretamente no preço (ou na margem de lucro) e na Qualidade final dos produtos. Uma vez que as empresas estão buscando a melhora da Qualidade, o fator custo dessa tem sido alvo das atenções dos empresários.

Segundo Leone (2000, p. 54), custo é "o consumo de um fator de produção medido em termos monetários para a obtenção de um produto, de um serviço ou de uma atividade que poderá ou não gerar renda". Nesse sentido, os custos são de competência do departamento de produção. Dentre esses custos encontram-se os custos da Qualidade e da não Qualidade.

Para Nascimento (2001, p. 25), custo é "o somatório dos bens e serviços consumidos ou utilizados na produção de novos bens ou serviços, traduzidos em unidades monetárias". 0 autor também amarra à definição de custos a produção de bens ou prestação de serviços.

Não basta controlar os custos, eles devem ser quantificados através de indicadores da qualidade que, segundo Piana e Erdmann (2011), revelam a maneira pela qual a organização obtém padrão de qualidade nos processos e nos produtos e atende às expectativas de seus clientes, por meio da adoção de programas de controle e redução de erros e imperfeições nos processos e produtos.

Custo da Má Qualidade é o resultado proveniente do fato de uma organização não produzir o produto corretamente desde a primeira vez (JURAN, 1991). Quando os produtos têm Má Qualidade, a empresa perde duas vezes: perde por produzir um produto que será rejeitado ou desclassificado e perde a oportunidade de produzir produtos bons.

\section{METODOLOGIA}

Este estudo de caso caracteriza-se como uma pesquisa exploratória, a qual tem como objetivo o fornecimento de critérios sobre a situação-problema enfrentada pelo pesquisador e sua compreensão, possibilitando o desenvolvimento de um processo de pesquisa flexível e não estruturado (MALHOTRA, 2001).

Os dados utilizados nesta pesquisa referem-se à produção dos itens classificados como "linha certificada" durante o período dos meses de fevereiro, março e abril do ano de 2010. 
Foram analisadas as peças produzidas com defeito da linha certificada, uma vez que a empresa não apresenta controle referente às demais peças produzidas.

Foi realizada uma entrevista com o Diretor Presidente, com o objetivo de coletar informações sobre sua percepção do negócio e sua, visão de futuro, sobre os valores da organização e, ainda, com o objetivo de analisar os ambientes interno e externo. Através das informações relatadas na entrevista, foi elaborada uma Matriz SWOT, destacando as potencialidades e reconhecendo as fraquezas da empresa. Uma vez ciente dos problemas, a empresa pode tomar atitude de defesa e estruturar estratégias para transformar suas fraquezas em oportunidades de crescimento.

A pesquisa para avaliar o Custo da Má Qualidade desenvolveu-se através da criação do Índice do Custo da Má Qualidade (ICMQ), que utilizou o levantamento dos dados do sistema da empresa através do cadastro de todas as peças que apresentaram defeitos ou medidas fora do limite de tolerância especificada no pedido, durante os meses de fevereiro, março e abril de 2010.

Com base nos dados do cadastro, foram relacionadas em uma tabela todas as peças que durante o processo de produção foram classificadas como "mortas", com os devidos códigos, as quantidades defeituosas, a máquina em que foram produzidas, a causa e, a classificação do defeito e o operador que o ocasionou, gerando a sucata ou possibilitando uma reelaboração da peça.

Para mensurar o custo da matéria-prima verificou-se o peso de cada peça, multiplicandose pelo custo do quilo da matéria-prima utilizada pela quantidade de peças produzida com defeito.

$\mathrm{Na}$ construção do custo operacional, foi realizado um levantamento do custo da hora/ máquina de cada operação no processo produtivo e o levantamento dos tempos e movimentos utilizados na fabricação de cada peça. Todos esses valores foram convertidos em minutos para facilitar os cálculos que se basearam no tempo de operação x custo do minuto de cada operação. Como cada peça apresenta uma sequência diferente de operações definidas nas Instruções de Trabalho, o custo foi calculado por cada código de peça até a operação em que esta foi classificada como "morta".

No que se refere ao custo com serviços terceirizados, foram englobado os custos com tratamento térmico e tratamento superficial realizados por outras empresas. Esses serviços são considerados como uma especificação técnica dos clientes, mas que agregam custos ao processo de fabricação. Nas peças que possuem essa especificação, foram adicionado esse serviços, considerando o custo da operação na unidade, mas não foi embutido o custo com transporte, devido à dificuldade de alocar o valor a unidade, pois, para tal, considera-se o peso do transporte e o valor total da nota.

Após a verificação do custo total, foi analisada a planilha de classificação que separa o que foi designado como sucata das peças que sofreram uma reelaboração, e seus relativos custos. Para realizar o levantamento da Perda da Receita de Vendas devido à Má Qualidade, compararam-se os preços de venda de cada peça retirados do sistema da empresa.

\section{RESULTADOS E DISCUSSÃO}

Inicialmente foi descrita a percepção do Planejamento Estratégico (PE) na empresa analisada, assim como a sugestão de uma definição do negócio da empresa e dos valores da organização. Posteriormente, elaborou-se uma Matriz SWOT e uma análise, baseada nas forças competitivas propostas por Porter (1990). Conforme apresentado nos objetivos, este capítulo apresentará também uma análise do Custo da Má Qualidade para empresa e o quanto esse fator influi na Perda de Receita de Vendas. 
4.1 Análise do ambiente interno e externo da empresa

Através da análise das questões referentes ao ambiente interno e externo da empresa foi possível construir uma Matriz SWOT, conforme segue no Quadro 1:

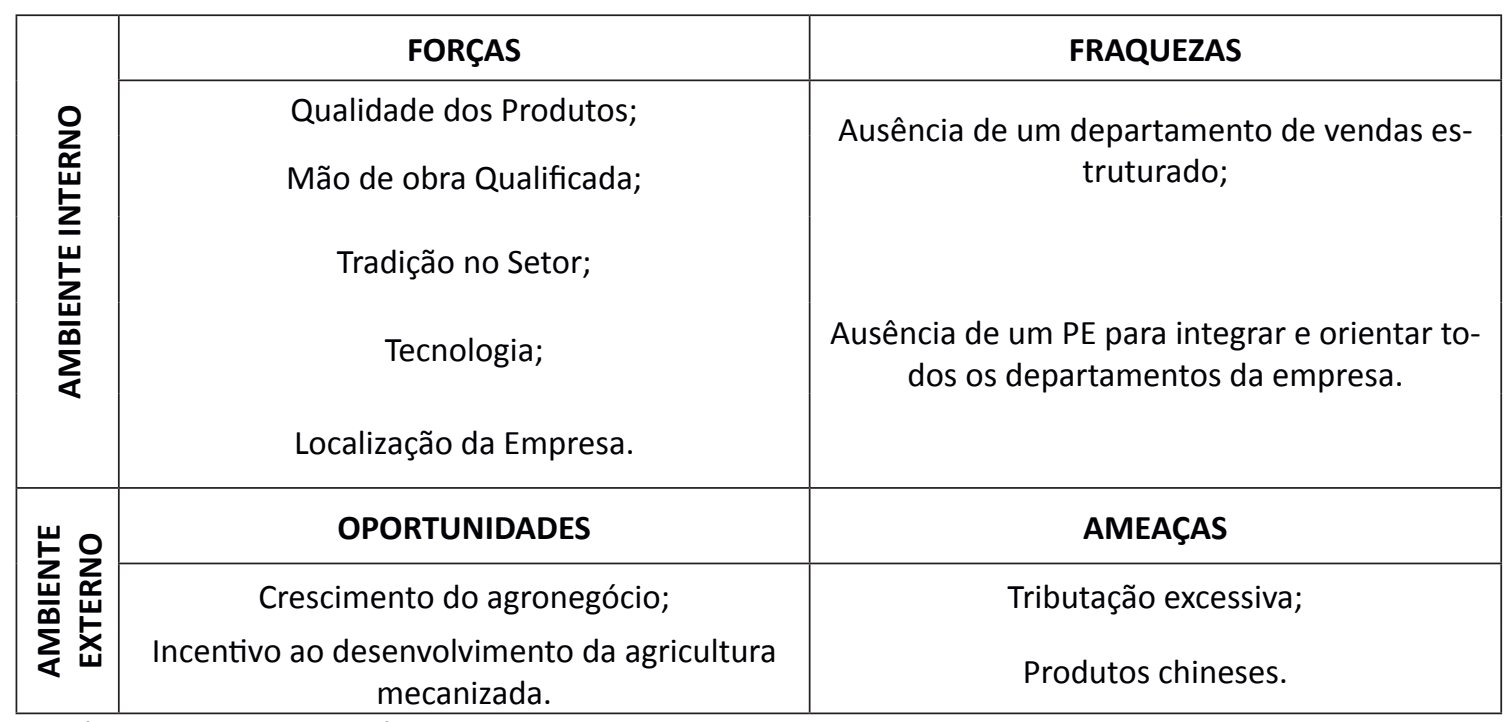

Quadro 1 - Matriz SWOT da empresa.

Através da análise dos dados, pode-se constatar que a empresa apresenta muitos pontos fortes e, principalmente, tradição no mercado e Qualidade reconhecida dos seus produtos. No entanto, a falta de estruturação da empresa, não permite que ela aproveite melhor as oportunidades existentes no mercado. Seu foco, assim, está em fornecer peças para as empresas do setor do agronegócio, o qual está em crescimento. De acordo com a Associação Nacional dos Fabricantes de Veículos Automotores (ANFAVEA), a produção de máquinas agrícolas avançou 9,5\% de janeiro a fevereiro de 2010. Em contraponto,em dezembro de 2009, foram fabricadas 5,88 mil unidades (LAGUNA, 2010).

O Ministério do Abastecimento estima que a safra nacional de grãos (cereais, leguminosas e oleaginosas) é de 146,87 milhões de toneladas; $8,7 \%$ milhões de toneladas superiores à produção obtida na safra 2008/2009 (CONAB, 2010). Esses dados confirmam o crescimento do agronegócio e, consequentemente, de toda a cadeia de suprimentos, na qual está inserida a empresa.

A localização do estado torna-se um ponto forte, pois no Rio Grande do Sul encontramse várias fábricas instaladas, e unidades de produção de montadoras.

A maior ameaça sofrida pela empresa são os fabricantes Chineses que, devido à falta de uma política social em seu país, possuem indústrias que dispõem de mão-de-obra barata e uma política tributária quase inexistente, favorecendo o seu crescimento industrial. Além disso, até poucos anos atrás a indústria chinesa não apresentava produtos com boa Qualidade e tecnologia, o que, atualmente, já não condiz com a realidade. Em vista disso, a empresa enfrenta essa ameaça apresentando diferencial na Qualidade e no atendimento aos clientes. 


\subsection{Análise do setor conforme as cinco Forças propostas por Porter}

\subsubsection{Poder de barganha dos fornecedores}

Após a análise pode-se classificar o poder de barganha dos fornecedores da empresa como forte, pois o setor é dominado por poucas empresas fornecedoras que apresentam comportamento cartelizado da principal matéria-prima utilizada (aço plano e perfis), o que não permite grande variação nos preços.

\subsubsection{Poder de barganha dos clientes}

Esta força competitiva diz respeito ao poder de decisão dos compradores sobre os atributos do produto, principalmente quanto a preço e Qualidade. Na empresa analisada, o poder de barganha dos clientes pode ser classificado como forte, uma vez que o faturamento da empresa se restringe a poucas montadoras e as compras do setor em grande volume.

Sendo assim, a empresa fica dependente dessa relação, pois não apresenta variabilidade na carteira de clientes. Se a empresa não apresentar preços atrativos de acordo com as exigências do mercado, poderá perder para a clientela para sua concorrência.

Como grande parte dos produtos são projetos dos clientes, a empresa não necessita estar sempre inovando seus produtos, mas deve estar sempre melhorando sua capacidade produtiva para atender a demanda. Os produtos a serem comprados são padronizados, sem grande diferenciação entre si.

\subsubsection{Ameaças de Novos Entrantes}

Pode-se classificar a Ameaça de Novos Entrantes como sendo, fraca devido ao capital necessário exigido para o investimento na instalação de novas empresas metalúrgicas é muito alto. Como a produção dessas empresas ocorre em grande escala, requer tecnologia específica, o que é um dos fatores mais relevantes para impedir o surgimento de novas empresas em um setor.

\subsubsection{Ameaças de Substitutos}

Os bens substitutos são aqueles que, embora sejam diferentes dos produtos originais, atendem a mesma necessidade. Quando há substitutos que apresentam melhoria na relação custo/benefício, e quando os custos do cliente para tal substituição são mínimos, as empresas devem ser observar os novos produtos com atenção especial.

Tendo em vista a evolução dos implementos agrícolas e a realidade do desenvolvimento brasileiro, a possibilidade de bens substitutos é muito pequena, ou quase inexistente. Isso se dá pelo fato de que, sejam quais forem os níveis de mecanização do setor agrícola, quase todas as máquinas apresentam engrenagens em sua estrutura mecânica, podendo apresentar diferenças apenas nas técnicas de fabricação utilizadas para aumentar o ganho de produtividade, ou na busca em reduzir a cadeia de engrenagens através de sistemas integrados de hidráulicos. Porém, esse processo só reduz a cadeia, não a extingue. 


\subsubsection{Rivalidade entre Concorrentes do Setor}

A Rivalidade entre Concorrentes do Setor pode-ser considerada a mais importante das cinco forças, especificamente neste setor, em que a agressividade dos concorrentes diretos é voraz, devido à tentativa de liderança quanto aos preços. Essa concorrência agrava-se, mais quando se trata de produtos oriundos da China, onde a produção se baseia em mão de obra barata e a política do comprometimento social é diferente das praticadas no Brasil, o que contribui para a prática de preços baixos. Dessa maneira, a empresa foca na tentativa de se diferenciar pelo atendimento e pelas técnicas de produção especializada na necessidade do cliente.

Considerando-se a análise das forças abordadas, especificamente na empresa em questão, fica evidente a fragilidade da empresa no que se refere a fornecedores e clientes, pois estas duas forças pressionam a empresa em sentidos opostos. Bicho e Baptista (2006), afirmam que quando os fornecedores constituem um alto poder de negociação, isso representa um importante fator de estrangulamento à rentabilidade da indústria. Quanto à força exercida pelos clientes a empresa fragiliza-se ao apresentar pouca diversificação na sua cartela de clientes. Atualmente, mais de 70\% do faturamento da empresa é gerado por dois clientes, o que aumenta o poder de barganha deles.

Outro aspecto importante é a rivalidade entre os concorrentes que, no setor metalúrgico, apresenta forte concorrência com os produtos chineses. Para solucionar esse problema, sugerese que a empresa busque a diversificação dos produtos e a diferenciação da Qualidade não somente nos produtos, mas também no atendimento aos clientes, buscando estreitar os laços da relação cliente-empresa.

\subsection{Análise do Custo da Má Qualidade}

Durante o período estudado, foi constado que a empresa tem como objetivo o reconhecimento de seus produtos pela Qualidade oferecida.

Porém, no que tange ao controle do Custo da Má Qualidade, a empresa não apresenta controle do custo dos produtos produzidos com defeitos, quando comparado com o faturamento líquido da empresa.

A Tabela 1 foi elaborada para analisar esse custo através do Índice do Custo da Má Qualidade (ICMQ, equação 1), que apresenta a seguinte estrutura:

$$
\text { ICMQ }=\frac{\text { Custo da má Qualidade }}{\text { Faturamento Líquido }} * 100
$$

Tabela 1 - Formação do Índice do Custo da Má Qualidade

\begin{tabular}{c|c|c|c}
\hline Indicador & Fevereiro & Março & Abril \\
\hline Custo da Má Qualidade & $\mathrm{R} \$ 2.239,70$ & $\mathrm{R} \$ 2.178,49$ & $\mathrm{R} \$ 2.463,29$ \\
Faturamento líquido & $100,00 \%$ & $168,82 \%$ & $95,87 \%$ \\
$\mathrm{ICMQ}$ & $0,58 \%$ & $0,45 \%$ & $0,91 \%$ \\
\hline
\end{tabular}

O faturamento líquido da empresa no período de fevereiro atingiu 100\%, apresentando variação nos meses seguintes. Para manter o sigilo empresarial, os valores não serão divulgados, tendo sido utilizados na integra apenas para a pesquisa.

O Custo da Má Qualidade na empresa foi considerado como aceitável pelo diretor geral da empresa, quando comparado com o faturamento líquido da mesma.A nova direção definiu como o índice do Custo da Má Qualidade até $1 \%$ do faturamento líquido da empresa. 
Em vista do período de amostragem, o faturamento líquido da empresa apresentou uma queda de mais de $50 \%$ no mês de Abril em relação ao mês anterior. Devido a isso, o Custo da Má Qualidade no processo de produção deveria ter sido reduzido de maneira proporcional. Porém, este fato não ocorreu, o que se pode constatar através do crescimento do ICMQ.

Conforme é possível constatar na Tabela 2, o Índice de Rejeição (IDR) representa o percentual de peças produzidas com defeito, comparadas com o total de peças produzidas pela empresa no período.

Tabela 2 - Formação do Índice de Rejeição.

\begin{tabular}{l|c|c|c}
\hline \multicolumn{1}{c|}{ Formação do Índice de Rejeição } & Fevereiro & Março & Abril \\
\hline Total de peças produzidas & 11.665 & 29.832 & 19.211 \\
Total de peças rejeitadas & 79 & 112 & 107 \\
IDR & $0,68 \%$ & $0,38 \%$ & $0,56 \%$ \\
Peças sucateadas & $80,37 \%$ & $82,06 \%$ & $70,40 \%$ \\
Peças Reelaboradas & $19,63 \%$ & $17,94 \%$ & $29,60 \%$ \\
\hline
\end{tabular}

Analisando-se a composição do custo total na fabricação de peças defeituosas, classificadas como sucata ou reelaboradas, no período dos meses de fevereiro, março e abril, observou-se o quanto a empresa desperdiça em matéria prima, serviços terceirizados, como tratamento térmico e superficial, e custo operacional, na fabricação de peças defeituosas. Conforme constatado na Figura 1, o maior custo refere-se ao custo operacional.

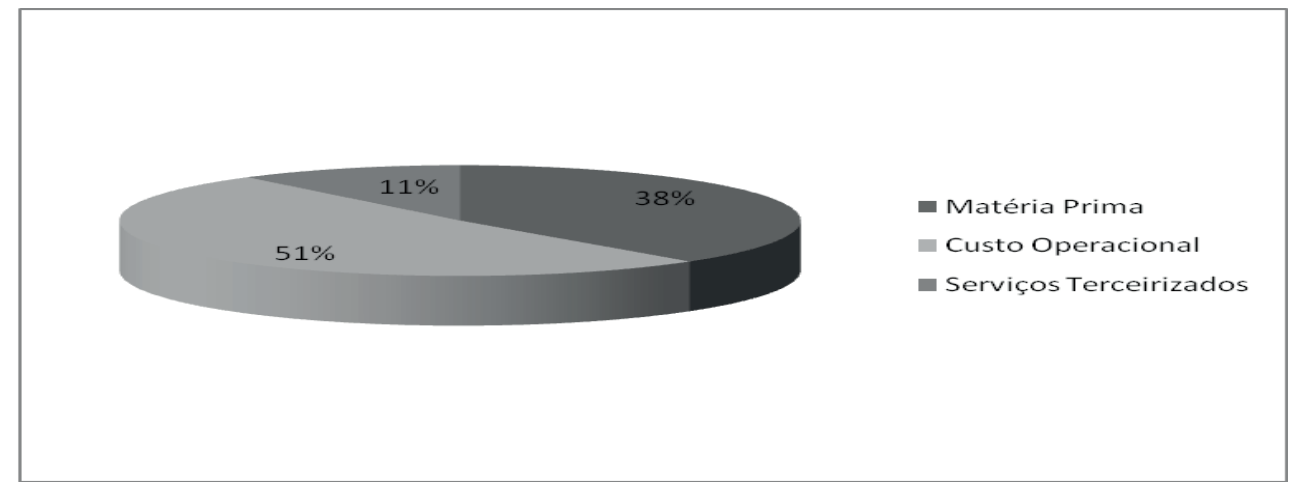

Figura 1 - Composição do Custo Total na fabricação de peças defeituosas pela empresa, de fevereiro a abril de 2010.

Corroborando com a importância do controle das falhas durante o processo, analisaramse todas as operações referentes à produção, com o objetivo de averiguar em quais operações as falhas acontecem com maior frequência.

Essa informação é de grande importância para que a empresa possa rever a questão das operações e do treinamento dos funcionários responsáveis por elas. Conforme apresentado na Figura 2, constata-se que o Torno com Comando Numérico Computadorizado (CNC) e as Furadeiras são as máquinas em que ocorre o maior número de falhas. No torno CNC, a justificativa das falhas é a alta precisão, pois qualquer comando ineficiente ou qualquer ajuste da máquina realizado de maneira inadequada pelo operador cria peças fora do padrão exigido pelo cliente. As operações realizadas nas furadeiras apresentam alto índice de falhas, pois, por ser considerada a operação mais simples o processo, tem como operadores, em sua maioria, estagiários ou profissionais iniciantes. Nota-se que a empresa necessita desenvolver um treinamento com os operadores das máquinas em questão. 


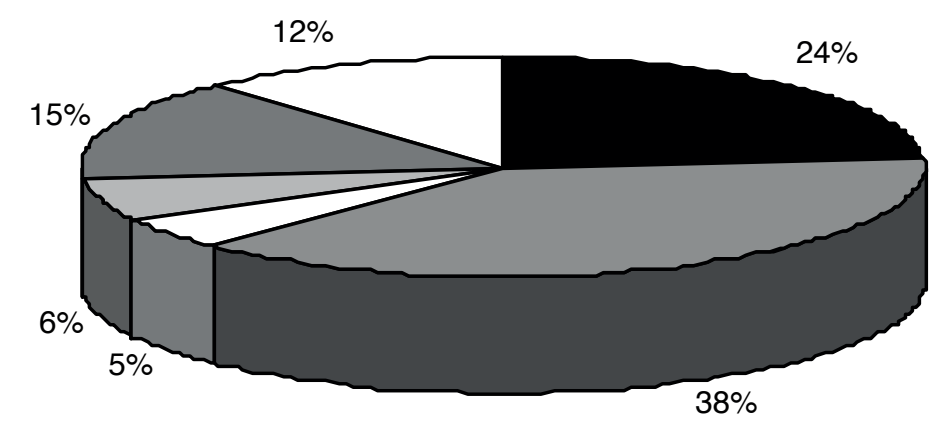

Figura 2 - Percentual de defeitos por tipo de máquina, de fevereiro a abril de 2010.

Esse levantamento foi de grande utilidade para a organização, pois, com base nos dados apresentados foi possível constatar sob quais as operações incidem os maiores número de defeitos, e, assim, organizar uma possível reavaliação dos funcionários responsáveis pelo manejo das máquinas, que são de extrema importância no processo de fabricação.

\subsection{Indicadores}

No que diz respeito aos indicadores, a empresa deveria refazê-los para que transpareçam a realidade vivenciada no processo produtivo.

Foi elaborado, com base em dados históricos das peças mortas, um gráfico para análise, possibilitando estimar uma média anual do índice de rejeição. Foi possível constatar, na Figura 4, que, após a mudança de gestão, a empresa apresentou uma diminuição em relação ao mesmo período do ano anterior. A Formação do Índice se deu pelo percentual da divisão do total de peças mortas pelo total de peças produzidas, conforme anteriormente apresentado na Tabela 2.

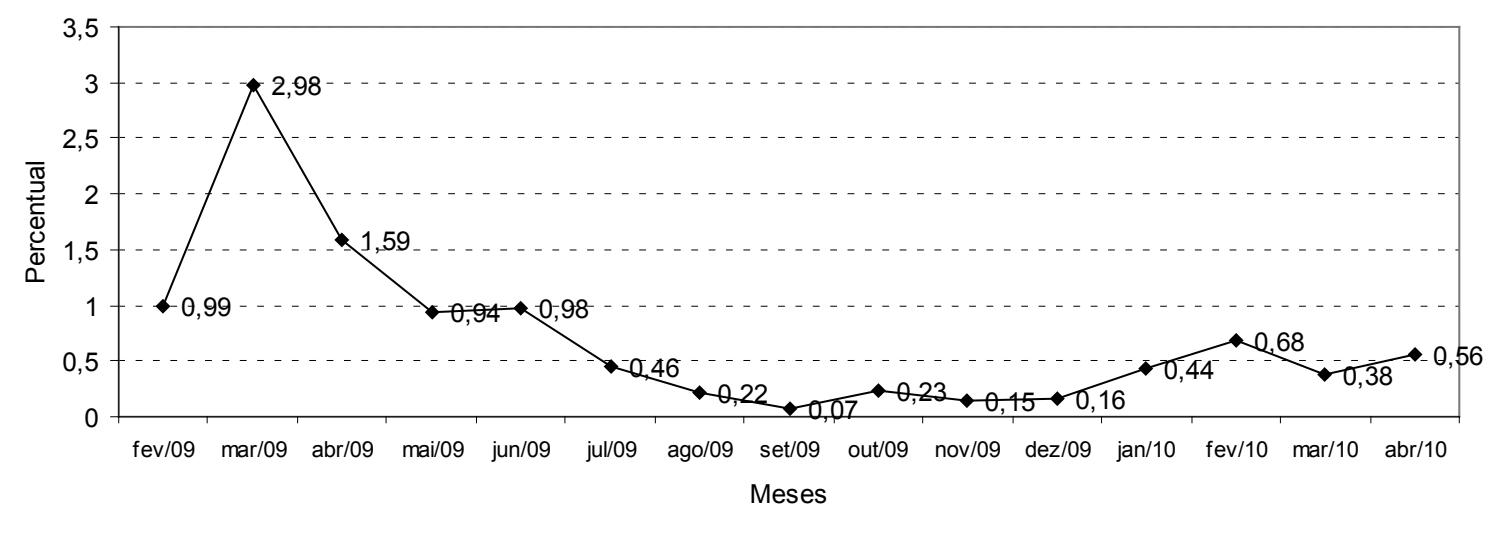

Figura 3 - Índice de Rejeição sugerido para a empresa.

Outra sugestão importante é que a empresa acompanhe a evolução das peças com defeito, classificadas como sucatas ou reelaboradas. A Figura 3 apresenta uma sugestão para este indicador, que permite boa visualização do processo de avaliação. 


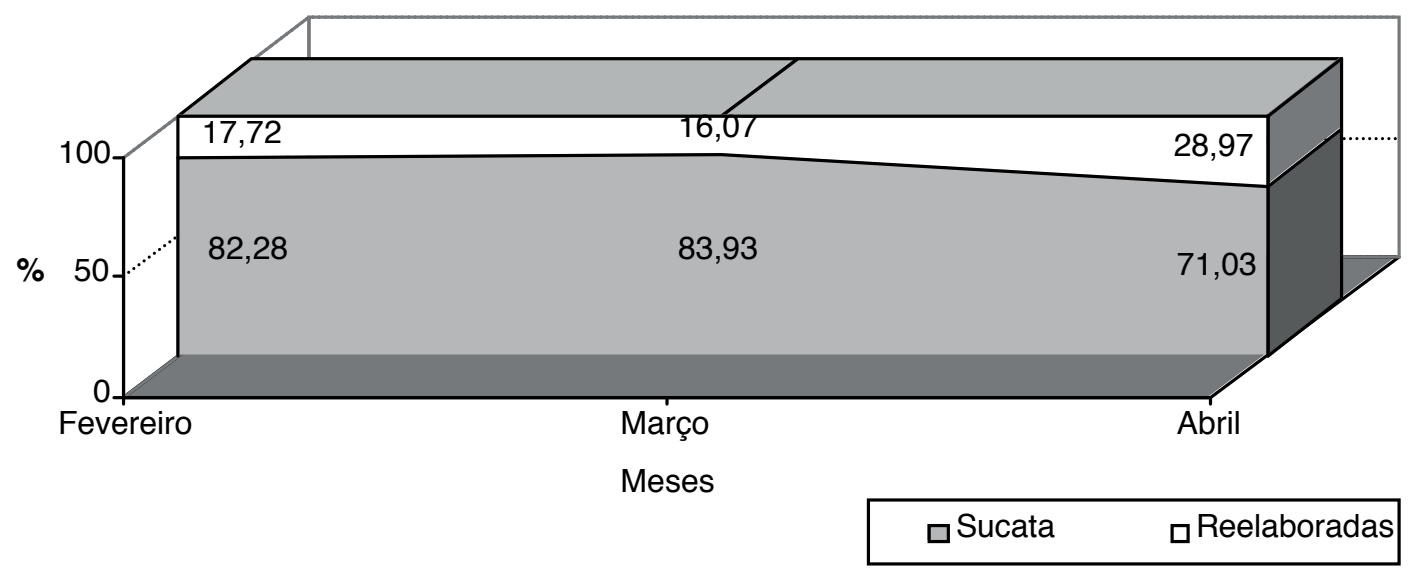

Figura 4 - Acompanhamento do desperdício.

Constatou-se que, mesmo que o número de peças com defeito não tenha diminuído, conforme apresentado na Tabela 3, a quantidade de peças produzidas que possibilitam o retrabalho apresentou crescimento, o que é um fator positivo para a empresa, uma vez que, nesse caso, a perda não é total, pelo contrário, as peças são vendidas no mercado de reposição, onde a margem de lucro para a empresa é ainda maior.

\subsection{Perda de Receita de Vendas na empresa}

Quanto às Perdas de Receita de Vendas devido à Qualidade, constatou-se, conforme apresentado na Tabela 4, que a empresa perdeu o correspondente a $0,96 \%$ do total do faturamento líquido da empresa, no período analisado.

Tabela 3 - Índice de Perda de Receita de Vendas.

\begin{tabular}{c|c|c|c|c}
\hline Indicador & Fevereiro & Março & Abril & Período Total \\
\hline Perda de Receita R\$ & $2.615,55$ & $3.418,11$ & $3.533,96$ & $9.567,62$ \\
IPRV & $0,92 \%$ & $0,71 \%$ & $1,24 \%$ & $0,96 \%$ \\
\hline
\end{tabular}

O IPRV foi considerado como aceitável por representar até $1 \%$ de faturamento total, mas requer atenção por parte da administração, uma vez que o faturamento da empresa diminuiu mais de $50 \%$ no mês de abril devido às férias coletivas do principal cliente da empresa. 0 índice IPRV requer um acompanhamento, pois, em períodos de baixa produtividade, a empresa deve reduzir seus custos para, consequentemente, reduzir suas perdas.

Foi através do levantamento desses valores que se constatou que a empresa estava com a Tabela de preços, de alguns itens, que são produzidos há mais tempo, abaixo do custo operacional. Tal fato este que se repetiu para alguns clientes. Isso explica-se devido a grande quantidade de itens que a empresa fabrica, o que gera dificuldade de atualizar ou mesmo de rever os preços praticados pela antiga gestão.

Essa informação foi de grande impacto para a empresa, pois requer uma atitude imediata e uma reavaliação dos preços praticados, e ainda uma atualização dos processos de fabricação dos itens mais antigos, que apresentaram divergência nas instruções de trabalho e na 
tomadas de tempos e movimentos, documentos que fornecem as informações utilizadas para a realização dos orçamentos praticados pela empresa.

\section{CONSIDERAÇÕES FINAIS}

Através da análise dos ambientes interno e externo, percebeu-se quais são as fraquezas e as forças existentes na empresa, dentre as quais se pode destacar, como fraqueza, a ausência dos departamentos administrativos e de vendas, que seriam responsáveis por projetar a empresa no mercado e colocar seus produtos em contato com um maior número de clientes e, como força, a qualidade dos seus produtos. Dentre as ameaças postas pelo meio externo, a empresa deve preocupar-se mais com a concorrência dos produtos oriundos da China, posto que as oportunidades no setor do agronegócio são variadas e estão em crescimento, conforme as informações apresentadas pela Companhia Nacional de Abastecimento (CONAB).

A análise baseada nas Forças propostas por Porter (1990) aborda a importância de que a empresa diversifique sua carteira de clientes, evitando a dependência e diminuindo a sua fragilidade quanto às imposições por eles colocadas, uma vez que já apresenta dependência em relação às imposições de alguns dos seus fornecedores que apresentam comportamento cartelizado.

No que se refere ao Custo da Má Qualidade vivenciado na empresa, concluiu-se que menos de $1 \%$ do faturamento líquido da empresa é perdido na produção de peças defeituosas, que a principal causa das falhas é falta de atenção ou o mau treinamento dos funcionários, e que os custos operacionais impactam em mais de $50 \%$ dos custos de fabricação. Durante o levantamento da Perda de Receita de Vendas devido à Má Qualidade, constatou-se que a empresa apresentava preços desatualizados e, em algumas peças, os valores eram inferiores aos custos operacionais da empresa.

Através desta pesquisa foi possível comprovar a real importância do controle dos custos da Qualidade e o quão significativas são as informações geradas por ela. Dessa maneira, pode-se mostrar que a Qualidade impacta em todos os setores da empresa, tanto no comercial, quanto no operacional, quanto no financeiro. Além disso, constatou-se que a empresa não deve ter uma visão voltada somente para a Qualidade, mas também para os custos que sua falta provoca na organização.

Conclui-se que, para verificar os benefícios que o programa da Qualidade traz para a empresa, deve ser realizada a mensuração dos custos das áreas, comparando com os resultados mais atuais com o dos períodos anteriores. Embora essa tarefa requeira certo trabalho, o benefício só será verificado com segurança se houver consistência no levantamento desses dados. Ter o domínio dos custos envolvendo a Qualidade e as falhas operacionais proporcionam que a empresa realize um trade-off entre os custos e a Qualidade, mantendo um equilíbrio racional dessas duas variáveis.Dessa forma, a empresa terá sucesso na estratégia competitiva de liderança em produtos de Qualidade.

Por último, é importante que todos os profissionais da empresa estejam envolvidos no sistema da Qualidade e, principalmente, comprometidos com o sistema da organização. 


\section{REFERÊNCIAS}

ALVES, I.; REZENDE, S. O.; OLIVEIRA NETO, O. J.; DREES, C.; FIGUEIREDO, R. S. Aplicação do modelo e análise SWOT no diagnóstico estratégico de uma propriedade rural especializada em recria e engorda de bovinos de corte. Revista Científica de Administração da Uni Evangélica, v. VI, p. 01-18. Goiânia: 2007.

ALMEIDA, T. A. N.; IDROGO, A. A necessidade de mensuração dos custos da Qualidade na estratégia competitiva de liderança nos custos. XXIV Encontro Nacional de Engenharia de Produção, Florianópolis, SC, Brasil, 2004.

BAISCH, L. V. Estrada, R. J. S., Scherer, F. L.; Hahn, I. S.; Thurner, B. Da V. Gestão Estratégia e as competências gerenciais no Departamento de Marketing: Estudo de uma Indústria de Bebidas. Revista de Administração da UFSM, Santa Maria, v. 5, Ed. Especial, p. 729-748. 2012.

BARBOSA, E. R.; BRONDANI, G. Planejamento estratégico organizacional. Revista Eletrônica da Contábeis. v. I. n . 2, 2005.

BICHO, L.; BAPTISTA, S. Modelo De Porter e Análise Swot: Estratégias De Negócio. Instituto politécnico de Coimbra, Instituto Superior De Engenharia De Coimbra, Departamento De Engenharia Civil, 2006.

CAMPOS, V. F. TQC: controle da Qualidade total (no estilo japonês). 2. ed., Belo Horizonte: Fundação Christiano Ottoni, Escola de Engenharia da UFMG, 1993.

TQC - Controle da Qualidade total (no estilo japonês). Belo Horizonte: Desenvolvimento Gerencial, 1999.

COSTA, B. D. Diretrizes para concepção, implementação e uso de sistemas de indicadores de desempenho para empresas da Construção civil; (Dissertação de Mestrado) - Programa de Pós-Graduação em Engenharia Civil - UFRGS, Porto Alegre, 2003.
COBRA, M. Estratégias de marketing de serviços. 2. ed., São Paulo: Cobra, 2001.

COLENGHI, V. M. O\&M e Qualidade Total - Uma Integração Perfeita. Rio de Janeiro, Qualitymark, 1997.

COLLINS, J. C.; PORRAS, J. C. Feitas para durar. 8 ed. São Paulo: Rocco, 2000.

COMPANHIA NACIONAL DE ABASTECIMENTO (CONAB): Acompanhamento de safra brasileira: grãos, sétimo levantamento, abril 2010 / Companhia Nacional de Abastecimento., Brasília: Conab, 2010.

ESTRADA, R. J. S. A eficiência e eficácia da gestão estratégica: Do planejamento estratégico à mudança organizacional. 2006.117f. Relatório apresentado ao Programa de Pós-Doutoramento FEA/USP, São Paulo, 2006.

FARIAS FILHO, J. R.; Gestão Estratégica pela Qualidade Total Percebida: do conceito a forma e da forma a prática. Rio de Janeiro, 1996. Tese (Doutorado em Engenharia de Produção) - Universidade Federal do Rio de Janeiro. 380 p.

FARIAS FILHO, J. R.; SALLES M. T. Como agir estrategicamente para implantar o processo de gestão estratégica pela Qualidade total? Universidade Federal do Rio de Janeiro ENGENEP. Rio de Janeiro, 1997.

FEIGENBAUM, A. V. Controle da Qualidade Total: Gestão e sistemas. São Paulo: Makron Boocks, 1994.

GAITHER, N.; FRAZIER G.; Administração da produção e operações. Tradução: José Carlos Barbosa Santos. 8 ed., São Paulo, Thomson Learning. 2001.

GALIZA, F.; CATUNGA, R. Uma Discussão sobre a Implantação de Modelos de Custos de Má Qualidade (CMQ) em Empresas de Seguros. 2004. 
GOMES, D. T.; Muniz, R. M.; Dias, A. T.; Gonçalves, C. A. Apresentação do processo de formação da estratégia: um estudo de caso em empresa inovadora. Revista de Administração da UFSM, Santa Maria, v. 5, n. 3, p. 413-438, set./dez. 2012.

JURAN, J. M.; GRYNA, F. M. Controle da Qualidade handbook: conceitos, políticas e filosofia da Qualidade. São Paulo: Makron Books, 1991.

JURAN, J. M. A Qualidade desde o projeto. 2. ed., São Paulo: Livraria Pioneira, 1994.

. Planejando para a Qualidade. 3. ed., São Paulo, Livraria Pioneira, 1995.

KAPLAN, R. S.; NORTON, D. P. A estratégia em ação: Balanced Scorecard. Rio de Janeiro: Campus, 1997.

\section{Organização orientada para a} estratégia: como as empresas que adotam - Balanced Scorecard prosperam no novo ambiente de negócios. Rio de Janeiro, Campus, 2001.

KOTLER, P. Administração de marketing: análise, planejamento, implementação e controle. 2. ed., São Paulo: Atlas, 1992.

Administração de marketing: a edição do novo milênio. São Paulo, Prentice Hall. 2000.

LEONE, G. S. G. Custos: planejamento, implantação e controle. São Paulo: Atlas, 2000.

LUTHER, W. M. Marketing Plan: da preparação à implantação. São Paulo: Maltese. 1992.

MACHADO, R.T.M.Estratégia ecompetitividade em organizações agroindustriais. Lavras: UFLA/FAEPE, 2005.

MALHOTRA, N. K. Pesquisa de marketing: uma orientação aplicada. 3. ed. Porto Alegre: Bookman, 2001

NASCIMENTO, J. M. Custos: planejamento, controle e gestão na economia globalizada. São Paulo: Atlas, 2001.

OLIVEIRA, D. P. R. Planejamento estratégico: Conceitos, metodologias e práticas. 18 ed. São Paulo: Atlas, 2002.

OLIVEIRA, M. A. L. Integração ISO 9000 e TQC. Revista Banas Qualidade. nov. 1999.

PALADINI, E. P. Gestão da Qualidade no processo: a Qualidade na produção de bens e serviços. São Paulo: Atlas, 1995.

PALADINI, E. P. Gestão da Qualidade: Teoria e Prática. 2.ed. São Paulo: Atlas, 2008

PIANA, J.; ERDMANN, R.H. Fatores geradores de competitividade na manufatura: uma relação entre práticas e resultados. Revista de Administração da UFSM, Santa Maria, V. 4, p. 73-90. Santa Maria: 2011.

PINHEIRO, M. Gestão e desempenho das empresas de pequeno porte. Tese (Doutorado em Administração), Faculdade de Economia, Administração e Contabilidade da Universidade de São Paulo - FEA/USP, São Paulo, 1996.

POLI, J. A; MACHADO, C. B. ISO 9001:2000 uma abordagem prática. 1 ed. São José dos Pinhais: Amaro, 2003.

PORTER, M. E. Vantagem competitiva: Criando e sustentando um desempenho superior. Rio de Janeiro: Campus, 1990.

ROBLES Jr, A. Custos da Qualidade. São Paulo: Atlas, 2003.

RODRIGUES, E. R. F.; LEMOS, A D. C. Indicadores da Qualidade e Qualidade ambiental em indústria fumageira. In: XXI Encontro Nacional de Engenharia de Produção. Anais, Faculdade de Tecnologia e Ciências, Salvador, BA, 2001.

SABINO, A. G. Estabelecimento de conjunto de indicadores de desempenho para suprir as exigências da norma ISO 9001 VERSÃO 2000. (Dissertação de Mestrado) - Programa de Pós-graduação em Engenharia de Produção - 
UFRGS, Porto Alegre, 2004.

SANTOS, I. P. Proposta de utilização do planejamento estratégico na preparação de um modelo geral. Programa de Pós-graduação em Engenharia de Produção - UFRGS, Porto Alegre, 2001.

SANTOS, S. R. Análise crítica de um método para implementação das normas ISO 9000 em pequenas e médias empresas brasileiras. (Dissertação de Mestrado) - Programa de Pós-graduação em Engenharia de Produção UFRGS, Porto Alegre, 2002.

SILVA, R. O. Teorias da administração. São Paulo: Pioneira Thomsom Learning, 2001.

SINK D. S.; TUTTLE, T. C. Planejamento e medição para performance. Rio de Janeiro: Qualitymark, 1993.

TAMAYO, A.; MENDES, A. M.; PAZ, M .T. Inventário de valores organizacionais. Universidade de Brasília, Brasilia, 2000.

TAVARES, M. C. Planejamento Estratégico: a opção entre o sucesso e fracasso empresarial. Herba. São Paulo, 1991.

VIEGAS, J. Estabelecimento de um sistema integrado de gestão: Qualidade e meio ambiente. Programa de Pós-graduação em Engenharia de Produção - UFRGS, Porto Alegre, 2000.

WRIGHT, P. KROLL, M. J; PARNELL, J. Administração Estratégica: conceitos. São Paulo: Atlas, 2000. 